\title{
So What If I Don't Have An iPhone? The Unintended Consequences Of Using Arrogance In Advertising
}

Haakon T. Brown, California State University, San Bernardino, USA

\begin{abstract}
Although the effects of arrogance on relationships have been studied within the field of personality and social psychology, there is a lack of research on the effects of corporate arrogance on relationships with consumers. In the current research, the author examines the effect of corporate arrogance (operationalized through the use of arrogance in a commercial) on consumers' attitudes toward the brand and on their purchase intentions toward the product. In one experiment the author demonstrates that the use of arrogance in commercials has opposite effects on attitudes depending on a consumer's previous experience with the brand. Specifically, individuals who are current users of the advertised product display an increase in attitudes, while those who do not currently use the advertised product demonstrate a decrease. Interestingly, the use of arrogance in commercials has a main effect on consumers' purchase intentions. Specifically, all consumers, regardless of their previous experience with the advertised product, exhibit lower purchase intentions toward said product. This work makes a significant contribution to the field as it suggests that companies need to be especially careful about utilizing arrogance in their advertising because it may generate the opposite effect than what was intended.
\end{abstract}

Keywords: Arrogance; Advertising; Effectiveness; Customer Acquisition; Brand Loyalty; Product Experience; Attitudes; iPhone

\section{INTRODUCTION}

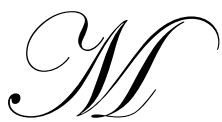

ost of us have encountered arrogant people at some point in our lives, people who thought a little too highly of themselves or belittled something you said or did. These encounters may have occurred at work or in social settings, but is it possible for corporations or brands to be perceived as arrogant, and if so, does it matter? In this paper, I examine the effects of corporate arrogance on attitudes and purchase intentions. First I review the literature on arrogance in relationships and posit how these effects might apply to consumers and corporations. Then, I present results from one experiment that tests these effects. Finally, I review the empirical results, discuss the theoretical contributions and managerial implications of this research, and suggest directions for future research.

\section{THEORY}

Arrogance has been defined as a chronic belief of superiority and exaggerated self-importance that is demonstrated through excessive and presumptuous claims (Hareli \& Weiner, 2000; Kowalski, Walker, Wilkinson, Queen, \& Sharpe, 2003; Leary, Bednarski, Hammon, \& Duncan, 1997). The extant literature on the effects of arrogance has mostly approached the topic from the area of personal relationships. This research suggests, for example, that an arrogant person is less liked than a modest one (Schlenker \& Leary, 1982; Wosinska, Dabul, Whetstone-Dion, \& Cialdini, 1996). Additional research has examined corporate arrogance but this is mostly limited to the behavior of individuals in the corporation and its effect on organizational behavior. For example, Leslie \& Van Velsor (1996) found that acting arrogant is one factor that precedes executive failure. There is also some evidence that demonstrates that arrogance can result in organizational failure (Boyd, 2001) and can serve as a leader-based trigger of destruction within organizations (Ma \& Karri, 2005). 
There is a considerable lack of research, however, investigating the marketing implications of corporate arrogance. For the purposes of this paper, corporate or brand arrogance is defined as behavior that communicates a company's or brand's exaggerated sense of superiority, which is often accomplished by disparaging others (Johnson, Silverman, Shyamsunder, Swee, Rodopman, Cho, \& Bauer, 2010). Given the goal of competitive advertisements to persuade consumers of the superiority of the target product, it is intuitive that consumers might interpret some marketing messages as arrogant, but the effects of this perceived arrogance on consumer attitudes and purchase intentions are more difficult to foresee. The existing research on arrogance in relationships predicts a main effect of corporate or brand arrogance on consumer attitudes such that consumers should like an arrogant corporation or brand less than a modest one, but these effects are not as clear cut.

Kowalski et al. (2003) demonstrated that victims of arrogance viewed the behavior more negatively than perpetrators of arrogance. In the case of corporate or brand arrogance, especially that perceived in product advertising, it is possible for ownership of the target product to lead consumers to take the perspective of the perpetrator of arrogance, while non-ownership would lead consumers to take the perspective of the victim of arrogance. It should follow then that prior target product ownership will moderate the effects of arrogance in advertising on attitudes toward the advertisement, brand, and target product. Specifically, non-owners of a target product should react negatively to the use of arrogance in advertisements for that product resulting in lower attitudes toward the advertisement, brand, and target product, while prior owners of the target product should demonstrate the opposite effect. Given the tenuous correlation between attitude and behavior, it is less clear what the downstream effects of these attitudes will be on purchase intentions toward the target product. These propositions are tested in the following experiment.

\section{EXPERIMENT}

The main objective of this study was to examine the effect of the use of arrogance in advertising on product and brand attitudes as well as purchase intentions. Additionally, given past research it was thought that previous ownership of the advertised target product would moderate the results.

In this study the Apple iPhone was used as the main stimulus target. The iPhone is a successful product line of smart phones developed and sold by Apple. The first iPhone was released on June 29, 2007 and it is currently in its fifth generation form (iPhone 4S). The product line has been extremely successful for Apple, generating an almost cult following. Additionally, Apple has launched successful marketing campaigns for each subsequent release of the iPhone.

Around the time of this experiment Apple had released a new iPhone 4 television campaign that appeared to demonstrate arrogance and was subsequently the driving force behind this paper. In the original campaign the thirty second commercials began with the announcer stating, "If you don't have an iPhone, you don't have ...," one of a number of features that the iPhone provided. These commercials then ended with the tagline, "Yup, if you don't have an iPhone, well, you don't have an iPhone." Anecdotal information also seemed to support the author's view that the first campaign was arrogant and bothered non-iPhone owners. In a quote taken from a review for a competing product on the Sprint website, the reviewer stated, "Blows away the iPhone. If you don't have an iPhone... SO WHAT! This is much better." (iLoveMoneyLines, 2011) Interestingly, a few months after the campaign launched Apple decided to subtly modify the new campaign without any explanation as to why they decided to do so. These modified commercials were identical to the originals, except for the tagline at the end of the spots, which was changed to highlight the feature once again. For example in the commercials used for this experiment, the app store was the highlighted feature so the end tagline was modified to, "The app store, just one more thing that makes an iPhone an iPhone." In the opinion of the author this subtle change appeared to significantly decrease the perceived arrogance of the commercials. Thus, these commercials seemed to serve as a good manipulation of arrogance in an advertising context. Additionally, given the success and prevalence of iPhone users in the population, it would be relatively easy to use iPhone ownership as an additional independent variable.

Consequently arrogance was operationalized through the two different Apple iPhone commercials viewed. Thus the experiment consisted of a 2 (arrogance: high vs. low) x 2 (ownership: yes vs. no) between subjects design. A significant interaction was expected. Specifically, it was predicted that current iPhone owners would exhibit a 
more positive response to the high arrogance commercials, while non-iPhone owners would exhibit a negative response. Reactions to the low arrogance commercial were predicted to be similar across ownership conditions.

\section{Method}

One hundred and seventy-seven undergraduate students participated in this experiment in exchange for either class participation credit or entry into a \$25 Amazon gift card raffle. It was conducted on the computer. Participants were told that we were working with companies to evaluate new television advertisements. They were told that they would be reviewing a television commercial and would then be asked to answer some questions about the commercial. (see Appendix 1 for links to the commercial videos on the web). Participants were then asked their distinct opinions of the advertisement, the iPhone, and Apple using three nine-point semantic differential scale items anchored on the following word pairs: Bad/Good, Unfavorable/Favorable, and Negative/Positive. Individuals were then asked how likely they would be to purchase an Apple iPhone in the next year ( 9 point semantic differential anchored on Not very likely/Extremely likely). Next individuals were asked if they currently owned and used an Apple iPhone as their primary cellular phone. Finally, demographic and ancillary measures were collected.

\section{Results}

Attitude Toward the Advertisement. The three items used to measure the attitude toward the advertisement were collapsed into a summary measure $(\alpha=.91)$ and run in a 2 (arrogance: high vs. low) x 2 (iPhone ownership: yes vs. no) ANOVA. A significant between subjects main effect of iPhone ownership was found, such that those individuals who currently owned and utilized an iPhone as their primary mobile phone reported a more positive attitude toward the advertisement than those individuals who did not own an iPhone, regardless of the arrogance manipulation $\left(M_{Y e s}=7.83\right.$ vs. $\left.M_{N o}=7.20 ; F(1,173)=4.55, p<.034\right)$. A marginally significant interaction effect was found between arrogance and ownership $(F(1,173)=3.25, p<.073)$. Planned comparisons of the ownership conditions within both high and low arrogance revealed a significant effect of ownership consistent with our predictions. Specifically, individuals in the high arrogance condition who currently owned an iPhone held a more favorable attitude toward the advertisement than those in the high arrogance condition who did not currently own an iPhone $\left(M_{Y e s}=8.07\right.$ vs. $\left.M_{N o}=6.99 ; F(1,88)=8.46, p<.005\right)$. There were no significant differences between the two ownership conditions for the low arrogance ad (see Table 1). No other effects were significant.

Attitude Toward the iPhone. The three items used to measure the attitude toward the iPhone were collapsed into a summary measure $(\alpha=.96)$ and run in a 2 (arrogance: high vs. low) x 2 (iPhone ownership: yes vs. no) ANOVA. A significant between subjects main effect of iPhone ownership was found, such that those individuals who currently owned and utilized an iPhone as their primary mobile phone reported a more positive attitude toward the iPhone than those individuals who did not own an iPhone, regardless of the arrogance manipulation $\left(M_{Y e s}=8.40 \mathrm{vs}\right.$. $M_{N o}=$ $7.45 ; F(1,173)=8.80, p<.003)$. Given that iPhone owners have direct experience with the product this result makes intuitive sense. Although no other effects were significant the pattern of results was similar to those of both the advertisement and Apple attitude measures (see Table 1). As such, planned comparisons of the ownership conditions within both high and low arrogance again revealed a significant effect of ownership consistent with our predictions. Specifically, individuals in the high arrogance condition who currently owned an iPhone held a more favorable attitude toward the iPhone than those in the high arrogance condition who did not currently own an iPhone $\left(M_{Y e s}=8.51\right.$ vs. $\left.M_{N o}=7.11 ; F(1,88)=10.42, p<.002\right)$. There were no significant differences between the two ownership conditions for the low arrogance ad. No other effects were significant.

Attitude Toward Apple. The three items used to measure the attitude toward Apple were collapsed into a summary measure $(\alpha=.97)$ and run in a 2 (arrogance: high vs. low) x 2 (iPhone ownership: yes vs. no) ANOVA. There were no significant main effects but there was a significant interaction between ownership and arrogance $(F(1,173)=$ $3.76, p<.054$ ) (see Figure 1), providing further support for our predictions. Planned comparisons of the ownership conditions within both high and low arrogance again revealed a significant effect of ownership consistent with our predictions. Specifically, individuals in the high arrogance condition who owned an iPhone held a more favorable attitude toward Apple than those in the high arrogance condition who did not own an iPhone $\left(M_{Y e s}=8.35\right.$ vs. $M_{N o}=$ 7.15; $F(1,88)=5.91, p<.017)$. iPhone ownership had no significant effect on attitude toward Apple within the low arrogance condition (see Table 1). No other effects were significant. 
Table 1: Summary Results

\begin{tabular}{|c|c|c|c|c|c|c|c|c|}
\hline \multirow{4}{*}{$\begin{array}{r}\text { Arrogance } \\
\text { iPhone Ownership } \\
\text { Dependent Variable }\end{array}$} & \multirow{2}{*}{\multicolumn{6}{|c|}{\begin{tabular}{l|l|l|} 
Low & & \\
\end{tabular}}} & \multirow{2}{*}{\multicolumn{2}{|c|}{ Total }} \\
\hline & & & & & & & & \\
\hline & Yes & No & Total & Yes & No & Total & Yes & No \\
\hline & & & & & & & & \\
\hline Ad Attitude & 7.49 & 7.40 & 7.42 & $8.07^{\mathrm{b}}$ & $6.99^{\mathrm{b}}$ & 7.29 & $7.83^{\mathrm{a}}$ & $7.20^{\mathrm{a}}$ \\
\hline iPhone Attitude & 8.24 & 7.77 & 7.86 & $8.51^{\mathrm{d}}$ & $7.11^{\mathrm{d}}$ & 7.50 & $8.40^{\mathrm{c}}$ & $7.45^{\mathrm{c}}$ \\
\hline Apple Attitude & 7.80 & 7.93 & 7.91 & $8.35^{\mathrm{e}}$ & $7.15^{\mathrm{e}}$ & 7.48 & 8.13 & 7.56 \\
\hline Purchase Intention & 7.47 & 5.64 & $6.00^{\mathrm{g}}$ & 5.84 & 4.60 & $4.94^{\mathrm{g}}$ & $6.50^{f}$ & $5.14^{1}$ \\
\hline
\end{tabular}

${ }^{\mathrm{a}, \mathrm{e}, \mathrm{g}}$ Significantly different, $p<.05$.

b, c, d, f Significantly different, $p<.005$.

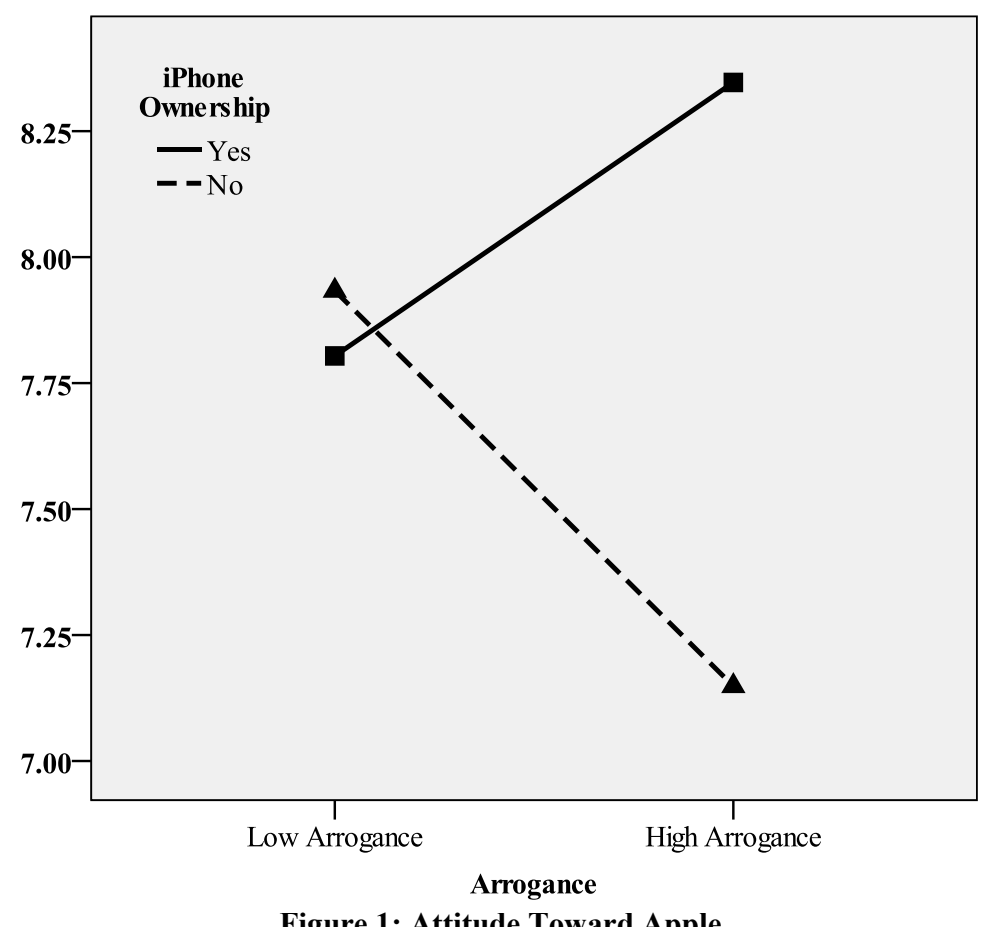

Figure 1: Attitude Toward Apple

Purchase Intention. The behavioral intention measure was run in a 2 (arrogance: high vs. low) x 2 (iPhone ownership: yes vs. no) ANOVA. A significant between subjects main effect of iPhone ownership was found, such that those individuals who currently owned and utilized an iPhone as their primary mobile phone were more likely to purchase an iPhone within the next year than those individuals who did not own an iPhone, regardless of the arrogance manipulation $\left(M_{Y e s}=6.50\right.$ vs. $\left.M_{N o}=5.14 ; F(1,173)=8.18, p<.005\right)$. Interestingly, a second between subjects main effect of arrogance was found, such that those individuals who saw the high arrogance commercial were less likely to purchase an iPhone within the next year than those individuals who saw the low arrogance commercial $\left(M_{\text {High }}=4.94\right.$ vs. $\left.M_{\text {Low }}=6.00 ; F(1,173)=6.21, p<.014\right)$ (see Figure 2$)$. No other effects were significant. 


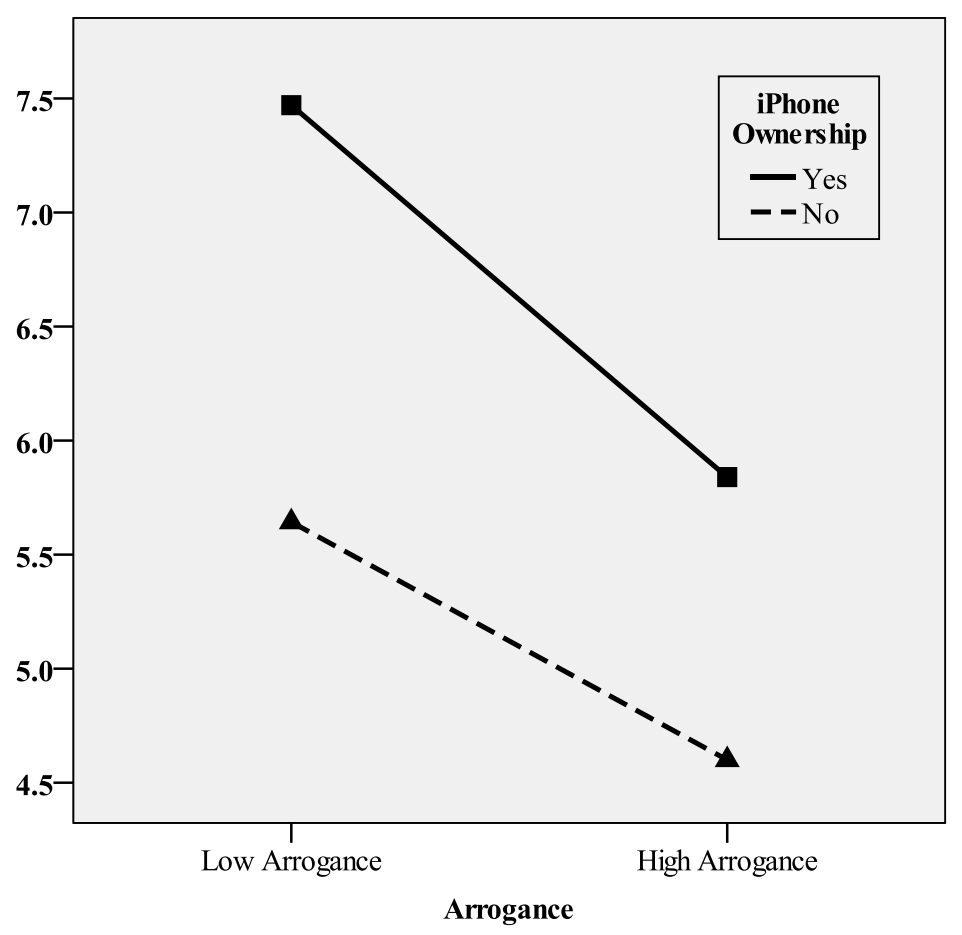

Figure 2: Purchase Intent

Manipulation Check. As a check of the arrogance manipulation, all individuals were asked to report how arrogant they believed the commercial to be. A ONE-WAY ANOVA analysis was conducted. Individuals in the high arrogance condition believed the commercial to be more arrogant than those in the low arrogance condition $\left(M_{H i g h}=\right.$ 5.92 vs. $\left.M_{\text {Low }}=4.70 ; F(1,175)=12.14, p<.001\right)$, confirming that our arrogance manipulation worked as intended. Additionally, individuals were also asked to report how arrogant they believe Apple to be. A ONE-WAY ANOVA analysis was conducted. Individuals in the high arrogance condition believed Apple to be more arrogant than those in the low arrogance condition $\left(M_{\text {High }}=5.94\right.$ vs. $\left.M_{\text {Low }}=4.90 ; F(1,175)=7.95, p<.005\right)$.

\section{GENERAL DISCUSSION}

The results from one experiment provide support for the hypothesized effect of arrogance in advertising on advertisement, brand, and product attitudes. Specifically, individuals who currently own target products react favorably to the use of arrogance in advertising by displaying higher attitudes toward the advertisement, brand, and product. Conversely, individuals who do not currently own target products react negatively to the use of arrogance in advertising by displaying lower attitudes toward the advertisement, brand, and product. Although attitude toward Apple was the only measure to reveal a significant interaction, all three attitude measures demonstrated a similar pattern of results and all three simple contrasts in the high arrogance condition were significant providing further support for our predictions. Yet how these effects on attitudes translate to purchase intentions is less clear. Certainly the main effect of current iPhone ownership on purchase intentions makes intuitive sense as individuals who currently own and use a product should be more likely to continue to use that product (or a newer version of that product) in the future. However the main effect of arrogance on purchase intentions was unanticipated, especially given the pattern of results for the attitude dependent measures. Nevertheless it was not that surprising considering the tenuous record of attitude / behavior correspondence in the extant literature. Further investigation is therefore required to understand why the moderated effect of the use of arrogance in commercials on attitudes does not directly translate to a similar effect on purchase intentions.

It is possible, however, that this measure is confounded with participant eligibility for an upgrade from his or her carrier since the purchase intention measure asked within the next year and most mobile phone customers 
must complete two year service agreements before they are again eligible for an upgrade. Although it is feasible for customers to switch carriers before the expiration of their contracts, nearly all would be required to pay early termination fees. Additionally, only some of the major mobile phone carriers carried the iPhone at the time of this experiment limiting the possibility of upgrade for consumers who are loyal to those carriers. These confounds should be controlled for in future research.

This research makes a number of significant contributions to the literature. First, this research is one of the first papers to examine the use of arrogance in advertising. Additionally, it provides insight into when the utilization of arrogance in advertising might be an effective strategy in practice. Specifically, its effectiveness would seemingly depend on the advertising objective. For example, if the objective is to maintain brand loyalty then the use of arrogance might actually serve to increase loyalty, while conversely if the objective is customer acquisition it might have the unintended consequence of driving customers away. This research also makes a contribution to the arrogance literature by replicating general arrogance effects across another domain while also investigating a potentially new moderator of these effects.

This research is not without limitations. Although a hypothesized mechanism for the moderating effect of ownership is offered (perpetrator of arrogance vs. victim of arrogance) it is not empirically tested. Future research should look to clarify this mechanism. Additionally, it is not known if these effects would replicate for consumers that own the brand but not the target product of the advertisement. However, data measures on ownership of other Apple products in addition to the iPhone were collected in this experiment and these measures seem to support the contention that these effects are unique to ownership of the target product as nearly all participants currently owned or had previous experience with an Apple product.

Future research might also examine other possible modifiers such as consumers' need for uniqueness which could potentially flip the effect. Specifically, individuals who are high in need for uniqueness and currently own the target product might react negatively to the use of arrogance by striving to distinguish themselves from the advertised brand, while individuals who are low in need for uniqueness might react positively to the use of arrogance because they would be motivated to conform.

What is certain is that companies need to be extremely careful about using arrogance in advertising in the future. Although it is unclear why Apple decided to subtly modify their original iPhone4 campaign, it is clear that they made the correct decision given that the main objective of their advertising campaign was likely to be new customer acquisition.

\section{AUTHOR INFORMATION}

Haakon Brown is an Assistant Professor of Marketing at California State University, San Bernardino. He holds a Ph.D. in marketing from the Kellogg School of Management at Northwestern University. His research interests include attitudes and consumer behavior, consumer self-control, cultural effects on consumption, and the consumption of sport. Prior to his academic pursuits, Haakon spent a number of years working in consulting. He also holds an MBA from the MIT Sloan School of Management. E-mail: hbrown@csusb.edu

\section{REFERENCES}

1. Ajzen, I., \& Fishbein, M. (2005). The influence of attitudes on behavior. In D. Albarracin, B. T. Johnson, M. P. Zanna (Eds.), Handbook of attitudes and attitude change: Basic principles (pp. 4-38). Mahwah, NJ: Erlbaum.

2. Hareli, S.,\&Weiner, B. (2000). Accounts for success as determinants of perceived arrogance and modesty. Motivation and Emotion, 24, 215-236.

3. iLoveMoneyLines (2011, October 5). Samsung Galaxy STM II, Epic 4G Touch customer review. In Sprint. Retrieved January 26, 2012, from http://reviews.sprint.com/profiles/5611v3redes/209AF2EC4B2D99AEE10343729DBEE278/profile.htm 
4. Johnson, R., Silverman, S., Shyamsunder, S., Swee, H., Rodopman, O. B., Cho, E. \& Bauer, J. (2010). Acting superior but actually inferior?: Correlates and consequences of workplace arrogance. Human Performance, 23, 403-427

5. Kowalski, R., Walker, S., Wilkinson, R., Queen, A., \& Sharpe, B. (2003). Lying, cheating, complaining, and other aversive interpersonal behaviors: A narrative examination of the darker side of relationships. Journal of Social and Personal Relationships, 20, 471-490.

6. Leary, M. R., Bednarski, R., Hammon, D., \& Duncan, T. (1997). Blowhards, snobs, and narcissists: Interpersonal reactions to excessive egoism. In R. M. Kowalski (Ed.), Behaving badly: Aversive behaviors in interpersonal relationships (pp.111-131). New York: Plenum.

7. Leslie, J. B.,\&Van Velsor, E. (1996). A look at derailment today: North America and Europe. Greensboro, NC: Center for Creative Leadership.

8. Ma, H., \& Karri, R. (2005). Leaders beware: Some sure ways to lose your competitive advantage. Organizational Dynamics, 34, 63-76.

9. Schlenker, B. R., \& Leary, M. R. (1982). Audiences' reactions to self-enhancing, self-denigrating, and accurate self-presentations. Journal of Experimental Social Psychology, 18, 89-104.

10. Wosinska,W., Dabul, A. J., Whetstone-Dion, R., \& Cialdini, R. B. (1996). Self-presentational responses to success in the organization: The costs and benefits of modesty. Basic \& Applied Social Psychology, 18, $229-242$. 


\section{APPENDIX}

High Arrogance Commercial:

http://www.youtube.com/user/Apple?blend=3\&ob=5\#p/u/23/i9FhnIGhOqY

Low Arrogance Commercial:

http://www.youtube.com/user/Apple?blend=3\&ob=5\#p/u/12/8gpUG3vxhfA 